\title{
Police De-Escalation Training \& Education: Nationally, Provincially, and Municipally
}

\author{
Lisa M. Deveau*
}

This article is related directly to the 6th International Law Enforcement E Public Health (LEPH) Virtual Conference in March 2021.

\begin{abstract}
In this critical review and social innovation narrative, the current literature on de-escalation and policing is reviewed. The following explores how services train recruits and experienced officers on de-escalation, conflict resolution, and crisis intervention skills. A limited environmental scan was completed to inquire about the number of hours dedicated to de-escalation training compared with tactical and combative training within Ontario law enforcement agencies. The environmental scan also considered how services respond to imminent mental heath crises, as some services rely on mental health professionals to respond to 911 emergencies with police officers, through the Mobile Crisis Team. Within the literature, questions are proposed about the government's role in overseeing policing, and why there fails to be any federally or provincially mandated training and approach to mental health and de-escalation within Canadian law enforcement. The author ultimately advocates for systemic change by highlighting the priorities, values, and contradictions within Canadian police services which have been influenced by colonization and patriarchal narratives.
\end{abstract}

\section{INTRODUCTION}

Police officers enter situations that are unfamiliar and unknown. Their skills and expertise are required to either diffuse a situation, detain a suspect, or restore civility. In each situation, an officer must critically assess and respond in order to ultimately preserve their own safety and the safety of the public. Given the responsibilities of police officers, it is reasonable to assume that their training is comprehensive and governed by research that supports evidence-based practices-research that highlights skills commonly needed and used by officers, which is then used to inform officer annual training. Further, it is assumed that the training incorporates invaluable skills that extend beyond tactical and combative measures to incorporate de-escalation, conflict resolution, and mediation.

Throughout Canadian law enforcement history, there appears a critical tension that remains influential today. Officers are expected to build trust and partnerships in their communities, by applying de-escalation and conflict resolution skills, while also being trained to have the strategic, combative, and tactical skills to protect public safety. This dichotomy remains prevalent within the officers' culture, duties, and legislation. Leaders in policing seem to prioritize tactical responses over peaceful resolution, undoubtedly stemming from historical influences of colonization and patriarchal narratives that continue to influence the profession and are perpetuated by governmental and regulatory bodies.

The following critical review explores de-escalation training in police education within Canada, focusing on the following questions: How is de-escalation taught to officers, and what strategies are used in teaching de-escalation? Are there national, provincial, and municipal standards for teaching de-escalation to police officers? Are services mandated to incorporate strategies that teach peaceful resolution during annual training? What other skills and training, such as use of force, are officers taught? What structural and systemic issues influence the prioritization of police training? Finally, the Ontario Ministry of the Solicitor General's role in training and educating Ontario officers is explored and discussed.

\section{Mental Health Response/Approaches}

Mental health responses make up a large portion of an officer's responsibilities. In some cities, mental health accounts for over $60 \%$ of the calls for service (Watson et al., 2008). De-escalation has been an effective and safe response that restores order and preserves the safety of both citizen and officer. In Canada, $98 \%$ of the calls for service required de-escalation, while only $2 \%$ of calls required forceful and 
combative responses (Public Safety Canada, 2015). Given the frequency of the need for de-escalation, the following will discuss the most common approaches used within law enforcement agencies that teach and guide officers how to de-escalate and respond to mental health-related crises.

There is a lack of research on the most promising approaches to training and responding to mental health crises within Canadian law enforcement. The most common approaches within Canada and the United Stated are the Crisis Intervention Training course (CIT) and the Mobile Crisis Team. Crisis Intervention Training originated in Memphis, Tennessee, as a 40-hour program that reduces excessive use of force and prevents injury to both officer and citizen by training officers on promising de-escalation skills (Watson et al., 2008). The more common approach within Canada is the Mobile Crisis Rapid Response Team (MCRRT) (also referred to as impact team, mobile crisis engagement team, mental health and engagement team or other variations depending on the service) in which front-line, specialized officers are paired with mental health professionals to respond to imminent emergencies. Within this team, officers assess perceived risks and threats, then allow mental health professionals the chance to de-escalate and respond to the person in crisis.

In evaluating the approaches, CIT was found to be effective in helping officers identify mental illness, reduce rates of arrest, and increase referrals to mental health services (Watson et al., 2008). However, overall, the research shows the MCRRT to be more effective than the CIT course in responding to, identifying, and de-escalating mental health crises (Coleman \& Cotton, 2010; Watson et al., 2008). It is important to highlight that the research methods and conclusions drawn are open to question. The current research measures the effectiveness of these approaches and courses by focusing predominantly on reduced hospital wait-times, the ability to divert people in crisis away from the judicial system, and reduced on-scene times, which do not necessarily equate to promising responses in which force/excessive force was not used by officers on the scene.

\section{Methods of Teaching De-Escalation}

Most services apply an interdisciplinary approach when teaching officers promising approaches to de-escalation and mental health awareness. Through collaboration, law enforcement agencies teach de-escalation by incorporating skills used by social workers, psychiatric nurses, and counselors. The training incorporates live testimonies/lived experiences, practical application of skills, group discussions, seminars, and lectures that identify and bring awareness of mental illness. The core goal of this training is to encourage officers to self-reflect, remain self-aware, and practice emotional regulation (Coleman \& Cotton, 2010; Krameddine et al., 2014; Richter et al., 2006; Watson et al., 2008).

\section{Application of Skills}

The CIT model incorporates a behavioural approach, in which officers apply acquired skills. The Edmonton Police Service (EPS) model, for example, dedicates a full day to simulated exercises as officers "respond" to carefully scripted, realistic scenarios performed by trained actors (Krameddine et al., 2014). The application of skills allows the actors, colleagues, and mental health professionals who provide the training to offer feedback on officers' presence, posture, tone, and verbal commands to encourage them to consider how they present themselves by tapping into self-awareness and selfreflection (Coleman \& Cotton 2010; Kisely et al., 2010, p. 663; Krameddine et al., 2013; Shapiro et al., 2015).

\section{Live Testimonies \& Lived Experience}

Incorporating live testimonies is another technique used in de-escalation training to increase empathy, patience, and understanding of mental illnesses as officers gain a first-hand account of a person's daily struggles. This provides officers the opportunity to observe and interact with a person when they are at their baseline and not experiencing a mental health crisis, which then makes them more capable of recognizing a person in crisis by identifying signs and symptoms. Lived testimonies also encourage officers to challenge any preconceived judgements and stereotypes they have about mental illness by giving them the opportunity to actively listen and ask questions (Coleman \& Cotton 2010; Kisely et al., 2010, p. 663; Krameddine et al., 2013; Shapiro et al., 2015).

\section{Lecture}

Any effective mental health course incorporates content that educates trainees on identifying mental illness and local mental health resources. Crisis Intervention Training incorporates lectures, seminars, and group discussions. Police officers who are trained and certified in CIT report having increased confidence in identifying and therefore de-escalating, mental health crises and referring citizens to appropriate mental health resources (Coleman \& Cotton, 2010; Kisely et al., 2010; Shapiro et al., 2015). Moreover, officers expressed that they learned to ask key questions when dealing with a person in crisis to help navigate the interaction (Coleman \& Cotton, 2010).

These are a few of the strategies used to teach deescalation, a skill that is arguably the most essential for officers. The requirements to become a police officer place a great deal of emphasis on physical strengths, perhaps at the expense of educational achievements. Recruits have experiences and educational qualifications that differ substantially from one candidate to the next. Officer annual training is the only standardized training officers receive and presents the best opportunity to teach essential skills to both novice and experienced officers. It is crucial that law enforcement agencies use the annual training time wisely and as an opportunity to educate officers on essential skills that might not be acquired otherwise.

\section{National and Provincial Standards}

A limited environmental scan was completed to explore how many hours law enforcement agencies dedicated, annually, to mental health and de-escalation training both within Canada and in the United States. In completing the scan, questions were asked regarding the number of hours dedicated to deescalation training and whether law enforcement agencies are provincially or nationally mandated to teach and instruct on de-escalation, conflict resolution, and crisis intervention.

The International Association of Directors of Law Enforcement Standards and Training (IADLEST) and International Association of Chiefs of Police \& Cincinnati University Center 
for Police Research \& Policy (IACP/UC) are two agencies that focus on evidence-based practices within policing in the United States. The IADLEST is an organization that rigorously evaluates and certifies courses that claim to equip officers with essential skills, such as a de-escalation (IADLEST, n.d.). Although it is not a requirement for law enforcement agencies to have this stamp of approval, most law enforcement agencies access and train officers using courses that have this certification (IADLEST, n.d.).

While IADLEST is an international organization that dedicates time and research to evidence-based police practices, including de-escalation and conflict resolution, most of their research involves educating and training officers in the United States. However, the research in relation to evidence-based de-escalation and mental health training for officers is lacking and outdated (IADLEST, n.d., IACP, n.d.). Other than the CIT model, the effectiveness of de-escalation training has not been well researched by professional and academic bodies (IADLEST, n.d., IACP, n.d.). According to researchers at the Center for Police Research and Policy at Cincinnati University, agencies are not required to allocate a certain number of hours to mental health, de-escalation, and conflict resolution training. Each police agency has discretion over the amount of time spent on de-escalation and crisis intervention training, and this training is not nationally mandated (IADLEST, n.d., IACP, n.d.). Agencies within each state arbitrarily dedicate hours to such training and often choose to prioritize use of force, combative, and tactical training over other essential skills, such as de-escalation, conflict resolution, and mental health awareness (IADLEST, n.d., IACP, n.d.). It is unclear whether there is an optimal number of hours for teaching de-escalation as "the research is just not there" (IADLEST, n.d., IACP, n.d.).

In Canada, the research record is just as thin. While most agencies use unique approaches in responding to mental health calls, such as the Kingston Police Service, Barrie Police Service, and Hamilton Police Service, which implement both the MCRRT and the Crisis Outreach and Support Team (C.O.A.S.T.) models, these models are not implemented consistently across Canadian law enforcement agencies. The MCCRT pairs a police officer with a mental health professional, and together this team responds to emergencies called in to local police forces, while C.O.A.S.T. officers follow-up on mental health-related calls for service after front-line officers have responded to and resolved the emergency. Officers who are part of C.O.A.S.T. ensure the person in distress is connected to mental health resources. However, the success of these models varies from service to service, as each agency applies a slightly different variation of the MCRRT and C.O.A.S.T. models. Furthermore, agencies are not mandated to have a mobile crisis team or a C.O.A.S.T. team. Therefore, some services use front-line officers, who are not well equipped to respond to and de-escalate mental health crises. Similar to the United States, there is a dearth of any published research that specifies how many hours, if any, each Canadian police agency dedicates to mental health and de-escalation training. There is also a lack of research on the effectiveness of mental health and de-escalation training, which makes it nearly impossible to train officers from an evidence-based perspective.

Considering that mental health calls make up a large percentage of the calls for service, and that over $75 \%$ of policeinvolved civilian fatalities in Canada involve a person who is experiencing a mental health crisis and/or is also under the influence of a substance, it is unclear why there appears to be minimal mental health and de-escalation training for officers (Nicholson \& Marcoux, 2018). Further, it is unknown why there is a lack of research to address this contradiction. Law enforcement agencies train from an enforcement approach which prioritizes proficient use of weapons. Within Ontario, training in baton strikes, hands-on combat, the use of oleoresin capsicum (OC) spray, and firearms use are all mandated by the Ministry of the Solicitor General through the Policing Standards Manual. The Manual does not mandate training hours for conflict resolution, de-escalation, and crisis intervention. It seems logical that officers would resort to their weapons when responding to high-stress situations, given that this is their training. This contradiction in the skills mandated by the government and the actual duties of a police officer should be further explored by asking the following key questions: Does law enforcement devote enough time to de-escalation training? Why does law enforcement continue to endorse use of force over de-escalation? What approaches in de-escalation training are promising? What is missing?

\section{Systemic/Structural Considerations}

Canadian law enforcement is regulated and mandated by provincial legislation and authority, which in theory oversee policing. Police forces are governed by provincial legislation, including the Police Services Act (in Ontario and Manitoba) and similar legislation in other provinces. Governing bodies specify how many hours of training each law enforcement agency must dedicate to specific skills and abilities. Deescalation, conflict resolution, and mediation are devalued, failing to garner appreciation and attention comparable with tactical and combative skills. Herein lies part of the issue: law enforcement agencies are not mandated to offer or evaluate mental health and de-escalation training.

The culture, organization, and structure of policing, including officer training and education, can be understood through a critical, historical, and structural lens. Policing began as a means to protect colonized land that was forcibly taken and occupied by European settlers (Nettelbeck \& Smandych, 2010). Through the establishment of the North-West Mounted Police (NWMP), conquered land was subsequently protected by the frontier police, who forcibly implemented law to protect the settlement schemes of European settlers (Nettelbeck \& Smandych, 2010). The NWMP was a paramilitary force that recruited officers with a military background (Nettelbeck \& Smandych, 2010). The relationship between the NWMP and Canada's First Nations and Métis peoples was one of mistrust and mistreatment at the hands of NWMP, "who viewed Indigenous peoples as inferior" (Nettelbeck \& Smandych, 2010). Policing and security continue to value this paramilitary enforcement model by continuing to endorse use of force over deescalation, conflict resolution, and crisis intervention. Officers are trained in a very traditional manner, oriented towards the legitimate "use of force," most of the training focusing on efficient use of weapons (Fielding, 2002).

Within Ontario, the Ministry of the Solicitor General perpetuates this paramilitary model, mandating agencies to meet specific and sometimes impractical training requirements (CANSEBP, 2020). The Ministry, the overarching 
governmental body in Ontario, imposes training requirements in collaboration with the Police Service Boards. The Policing Standards Manual directs law enforcement agencies to dedicate a certain number of training hours to baton strikes, oleoresin capsicum spray, and firearms (CANSEBP, 2020), requiring a minimum number of training hours dedicated to firearm requalification annually (Ontario Ministry of the Solicitor General, 2000). Yet they do not enforce, review, or evaluate de-escalation and conflict resolution training across Ontario (CANSEBP, 2020).

\section{Questions that Remain}

Research within policing is needed, specifically around officers' approach to de-escalation, conflict resolution, and mental health training so that law enforcement agencies can train officers in the response to mental health crises from an evidence-based perspective. While there is some research on the MCRRT and CIT, much of it is outdated. This begs the question, are law enforcement agencies reluctant to work with academic researchers? If so, why have agencies not been compelled to collaborate with academic scholars by the Ministries who oversee policing? Police services trained from an evidence-based perspective could perform optimally, and agencies' practice could be informed by collaboration with academic researchers.

Research has concluded that force is minimally used by officers, with "use of force" making up roughly $2 \%$ of all interactions (Government of Canada, 2015). Why does the Ministry of the Solicitor General then continue to emphasize use of force training? Are these standards informed by research? How can officers who are trained from a use-offorce perspective, as opposed to a de-escalation approach, have the skills to effectively de-escalate when called to do so?

\section{CONCLUSION}

There is a contradiction within policing, one that explains the current political and social climate around police officers addressing and responding to mental health calls. The lack of de-escalation, conflict resolution, and crisis intervention training for officers, coupled with a lack of research that evaluates the effectiveness of the training, contributes to the poor responses led by police and the current pressures facing law enforcement. As this impacts policing on a national level, the burden of overcoming this shortfall should not be placed solely on the agencies themselves, but on the regulating governing bodies that are expected to mandate and oversee policing. Officers have never claimed to be mental health professionals; they have been forced into a position of responding to mental health crises due to a lack of resources and responses to mental health. While it is certainly vital to train officers on use of force, it is arguably more important to train them on de-escalation, conflict resolution, and crisis intervention as it is more pertinent to their daily responsibilities as officers.

\section{ACKNOWLEDGEMENTS}

I would like to acknowledge Dr. Susan Braedley, my supervisor for the Crisis Intervention and Policing course I created.

CONFLICT OF INTEREST DISCLOSURES

The author has no conflicts of interest to declare.

\section{AUTHOR AFFILIATIONS}

* Department of Social Work, Carleton University, Ottawa, ON, Canada.

\section{REFERENCES}

Canadian Society of Evidence Based-Policing [CANSEBP]. (2020). CANSEBP Policy. Author. https://www.can-sebp.net/policy

Coleman, T., \& Cotton, D. (2010). Reducing risk and improving outcomes of police interactions with people with mental illness. Journal of Police Crisis Negotiations: The Police and People with Mental Illness: New Approaches to a Longstanding Problem, 10(1-2), 39-57. https:// doi.org/10.1080/15332581003756950

Fielding, N. G. (2002). Theorizing community policing. British Journal of Criminology, 42(1), 147-163.

Government of Canada. (2015). Collection and Analysis of Data on the Use of Force. Public Safety Canada.

International Association of Directors of Law Enforcement Standards and Training [IADLEST]. (n.d.). National Certification Program. Author. https://iadlest-ncp.org/

International Association of Chiefs of Police [IACP]. (n.d.) Center for Police Research and Policy. Author. https://www.theiacp.org/research

Kisely, S., Campbell, L., Peddle, S., Hare, S., Pyche, M., Spicer, D., \& Moore, B. (2010). A controlled before-and-after evaluation of a mobile crisis partnership between mental health and police services in Nova Scotia. The Canadian Journal of Psychiatry, 55(10), 662-668. https://doi.org/10.1177/070674371005501005

Krameddine, Y., Silverstone, P., \& Krameddine, Y. (2014). How to improve interactions between police and the mentally ill. Frontiers in Psychiatry, 5, 186-191. https://doi.org/10.3389/fpsyt.2014.00186

Krameddine, Y., Demarco, D., Hassel, R., Silverstone, P., \& Krameddine, Y. (2013). A novel training program for police officers that improves interactions with mentally ill individuals and is costeffective. Frontiers in Psychiatry, 4, 9. https://doi.org/10.3389/ fpsyt.2013.00009

Nettelbeck, A., \& Smandych, R. (2010). Policing Indigenous peoples on two colonial frontiers: Australia's Mounted Police and Canada's North-West Mounted Police. Australian \& New Zealand Journal of Criminology, 43(2), 356-375. https://doi.org/10.1375/ acri.43.2.356

Nicholson, K., Marcoux, J. (2018, April 5). Most Canadians killed in police encounters since 2000 had mental health or substance abuse issues. CBC News. https://newsinteractives.cbc.ca/longformcustom/deadly-force

Ontario Ministry of the Solicitor General. (2000). Policing Standards Manual.

Public Safety Canada. (2015, December 03). Collection and analysis of data on the use of force. Government of Canada. Retrieved February 19, 2021, from https://www.publicsafety.gc.ca/cnt/rsrcs/pblctns/ cllctn-nlss-dt-frc/index-en.aspx

Richter, D., Richter, D., \& Whittington, R. (2006). Nonphysical conflict management and de-escalation. In D. Richter (Ed.), Violence in mental health settings: Causes, consequences, management (pp. 125-144). Springer Science \& Business Media, LLC.

Shapiro, G., Cusi, A., Kirst, M., O'Campo, P., Nakhost, A., Stergiopoulos, V., \& Shapiro, G. (2015). Co-responding policemental health programs: A review. Administration and Policy in Mental Health, 42(5), 606-620. https://doi.org/10.1007/ s10488-014-0594-9

Watson, A., Morabito, M., Draine, J., \& Ottati, V. (2008). Improving police response to persons with mental illness: A multi-level conceptualization of CIT. International Journal of Law and Psychiatry, 31 (4), 359-368. https://doi.org/10.1016/i.iilp.2008.06.004 